\title{
Article \\ Evaluation of Heterocyclic Carboxamides as Potential Efflux Pump Inhibitors in Pseudomonas aeruginosa
}

\author{
Yi Yuan ${ }^{\dagger}$, Jesus D. Rosado-Lugo ${ }^{\dagger}$, Yongzheng Zhang, Pratik Datta, Yangsheng Sun, Yanlu Cao, Anamika Banerjee \\ and Ajit K. Parhi *
}

check for updates

Citation: Yuan, Y.; Rosado-Lugo, J.D.; Zhang, Y.; Datta, P.; Sun, Y.; Cao, Y.; Banerjee, A.; Parhi, A.K. Evaluation of Heterocyclic Carboxamides as Potential Efflux Pump Inhibitors in Pseudomonas aeruginosa. Antibiotics 2022, 11, 30. https://doi.org/ 10.3390 /antibiotics 11010030

Academic Editors: Karl Hansford and Marc Maresca

Received: 5 November 2021 Accepted: 23 December 2021 Published: 28 December 2021

Publisher's Note: MDPI stays neutral with regard to jurisdictional claims in published maps and institutional affiliations.

Copyright: (c) 2021 by the authors. Licensee MDPI, Basel, Switzerland. This article is an open access article distributed under the terms and conditions of the Creative Commons Attribution (CC BY) license (https:// creativecommons.org/licenses/by/ $4.0 /)$.
TAXIS Pharmaceuticals, Inc., 9 Deer Park Drive, Suite J-15, Monmouth Junction, NJ 08852, USA; yyuan@taxispharma.com (Y.Y.); jrosado@taxispharma.com (J.D.R.-L.); yzhang@taxispharma.com (Y.Z.); pdatta@taxispharma.com (P.D.); yangsheng.sun@gmail.com (Y.S.); yanlucao@gmail.com (Y.C.); anamikabanerjee375@gmail.com (A.B.)

* Correspondence: aparhi@taxispharma.com; Tel.: +1-732-230-3074

t These authors contributed equally to this work.

\begin{abstract}
The ability to rescue the activity of antimicrobials that are no longer effective against bacterial pathogens such as Pseudomonas aeruginosa is an attractive strategy to combat antimicrobial drug resistance. Herein, novel efflux pump inhibitors (EPIs) demonstrating strong potentiation in combination with levofloxacin against wild-type P. aeruginosa ATCC 27853 are presented. A structure activity relationship of aryl substituted heterocyclic carboxamides containing a pentane diamine side chain is described. Out of several classes of fused heterocyclic carboxamides, aryl indole carboxamide compound $\mathbf{6 j}$ (TXA01182) at $6.25 \mu \mathrm{g} / \mathrm{mL}$ showed 8-fold potentiation of levofloxacin. TXA01182 was found to have equally synergistic activities with other antimicrobial classes (monobactam, fluoroquinolones, sulfonamide and tetracyclines) against $P$. aeruginosa. Several biophysical and genetic studies rule out membrane disruption and support efflux inhibition as the mechanism of action (MOA) of TXA01182. TXA01182 was determined to lower the frequency of resistance (FoR) of the partner antimicrobials and enhance the killing kinetics of levofloxacin. Furthermore, TXA01182 demonstrated a synergistic effect with levofloxacin against several multidrug resistant $P$. aeruginosa clinical isolates.
\end{abstract}

Keywords: Pseudomonas aeruginosa; RND efflux pumps; efflux pump inhibitors; heterocyclic carboxamides; antimicrobial drug resistance

\section{Introduction}

Efflux is one of the major resistance mechanisms in Gram-negative bacteria [1,2]. Efflux pumps are transporter proteins involved in the extrusion of a wide range of antimicrobials from the bacterial cell [3]. Many of these efflux pumps in Gram-negative bacteria belong to the resistance-nodulation-cell division (RND) family of tripartite efflux pumps [4,5]. The RND efflux systems in Pseudomonas aeruginosa consist of many identified efflux pumps that are largely responsible for its multidrug resistance [6]. Four well characterized multidrug efflux pump systems (MexA-MexB-OprM, MexC-MexD-OprJ, MexE-MexF-OprN, and MexX-MexY-OprM) are prevalent in multiple clinical isolates of P. aeruginosa [7]. In a recent study it was reported that in 30 clinical strains of $P$. aeruginosa, overexpression of mexB, mexF and mexY was detected in 27, 12, and 45\% of the clinical strains, respectively [8]. Additionally, P. aeruginosa possesses six RND efflux pumps (MexJK, MexGHI-OpmD, MexVW, MexPQ-OpmE, MexMN, and TriABC-OpmH) which might contribute to resistance at the clinic [9]. Approaches for circumventing efflux-mediated resistance require the development of direct, as well as indirect, antimicrobial agents. New antibiotics that are poor substrates of efflux pumps can serve as direct antimicrobial agents. On the other hand, indirect antimicrobial agents involve novel drugs that need to be paired with antimicrobials that have been rendered inactive by efflux. Due to dwindling pipelines for 
new antibiotics, inhibition of efflux pumps has become an attractive avenue to rejuvenate older antimicrobials to tackle the antibiotics resistance problem [10,11]. An ideal efflux pump inhibitor (EPI) would efficiently block these pumps, increasing the concentrations of the antimicrobials within the cell, thus rendering them effective again [12].

A variety of chemical scaffolds have been shown to act as EPIs (Figure 1). Among the first EPIs is the peptidomimetic MC-207,110 (Phenylalanine-arginine $\beta$-naphthylamide $(\mathrm{PA} \beta \mathrm{N})$ ), and related dipeptide amide compound, MC-04,124. Both were developed by Essential Therapeutics Inc and were shown to potentiate levofloxacin effectively in wild-type and efflux-pump-overexpressed $P$. aeruginosa strains [13,14]. A non-peptidomimetic lead series worthy of mentioning is D13-9001, the lead candidate from a novel pyridopyrimidine scaffold-based series developed for MexAB-OprM specific RND-pump inhibition [15]. A more recent endeavor involves MBX-2319, from a pyrazolopyridine class of compounds that potentiates ciprofloxacin, levofloxacin, and piperacillin against E. coli [16]. However, the development of these compounds has stopped or stalled for various reasons. PA $\beta N$ and related compounds showed prolonged accumulation in tissues associated with renal toxicity [17]. MC-04,124 was discontinued following the closure of Essential Therapeutics [18]. The MBX EPI series does not inhibit efflux in P. aeruginosa and, thus, may not be suitable for anti-pseudomonal therapy [19]. Despite presenting good in vitro activity and being efficacious in vivo against P. aeruginosa, D13-9001 is yet to progress to clinical evaluation [20]. Thus, the discovery of novel EPI scaffolds active against Gram-negative pathogens, particularly P. aeruginosa, with the potential of clinical use is still needed.

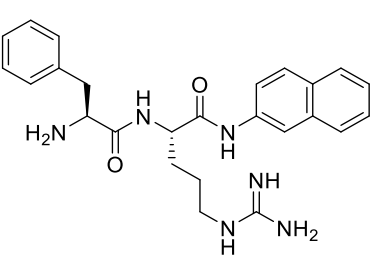

$\operatorname{PA} \beta N(M C-207,110)$

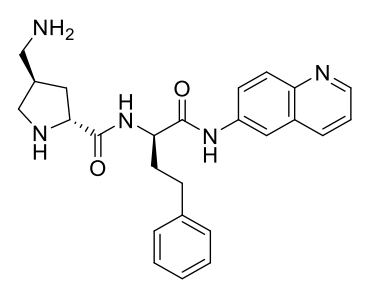

MC-04,124

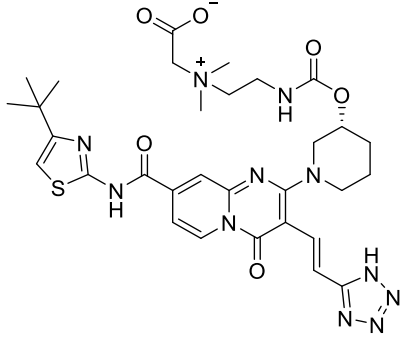

D13-9001

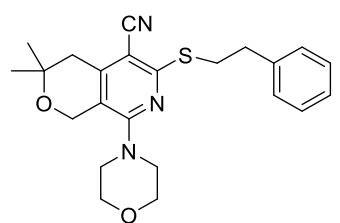

MBX-2319

Figure 1. Chemical structures of representative lead efflux pump inhibitors.

While no EPI so far has been approved for clinical use due to various reasons $[17,21]$, the need to combat antimicrobial resistant Gram-negative pathogens, especially ESKAPE pathogens (Enterococcus faecium, Staphylococcus aureus, Klebsiella pneumoniae, Acinetobacter baumannii, P. aeruginosa, and Enterobacter species), is of urgent medical need [22]. TAXIS Pharmaceuticals is committed [23] to finding solutions to multidrug resistant bacterial infections, and has recently published preliminary efforts on a diaminopentanamide class of potentiators (Figure 2) [24,25]. These potentiators had a hydrophobic arylalkyl or hetero aryl alkyl head groups linked by either an amide (compound 1) or by a reversed amide (compound 2) to chiral diamines. Interestingly, while amide $\mathbf{1}$ enhances the activity of the macrolide clarithromycin by 4-fold against E. coli ATCC 25922, the reversed amide 2 showed 16-fold potentiation at $12.5 \mu \mathrm{g} / \mathrm{mL}$ against E. coli ATCC 25922 with clarithromycin. Cell-based membrane permeabilization assays have determined an undesired mixed mode of action with these initial hits. Additionally, cationic amphiphilic molecules from this series were deemed too risky for further development, as they are prone to intracellular accumulation. The present study aims to find a development-worthy EPI series with better solubility, low lipophilicity and appreciable microsomal stability, which will serve as a starting point for a more elaborate optimization process. Lessons learned from the failure of earlier programs have been considered carefully as TAXIS continues to reach its goal of a first-in-class EPI-antibiotic combination treatment option against P. aeruginosa infections. 


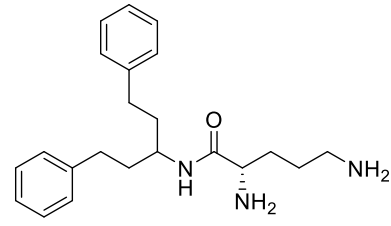

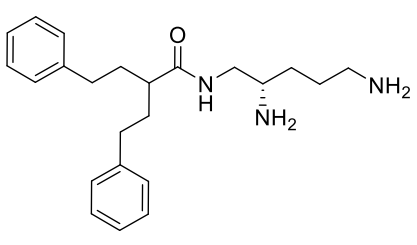

Figure 2. Structures of the two-aryl alkyl diaminopentanamide potentiators.

This report presents the results of a synthetic screen seeking to replace the aryl alkyl head groups by more druggable fragments connected to the chiral triamine 5 side chain of compounds $\mathbf{1}$ and $\mathbf{2}$ [24,25] (Figure 3). A key design aspect of this effort was to eliminate membrane disruption, a MOA seen in other EPI programs. It is anticipated that toxicity due to nonspecific binding may be eliminated or reduced with efflux specific mechanisms. Another aim of this series is to improve the metabolic and serum stability of the EPI molecules as compared to the peptide or peptidomimetic EPIs, which may benefit their potential development in the future. This work produced TXA01182, a novel EPI that enhances the activity of multiple classes of antimicrobials with efflux liabilities in wild-type and multidrug-resistant clinical isolates of $P$. aeruginosa, while playing a minimal role in membrane disruption and avoiding the onset of resistance.

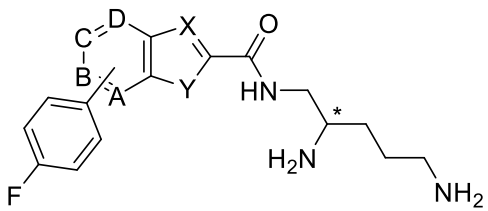

$\mathrm{A}, \mathrm{B}, \mathrm{C}, \mathrm{D}, \mathrm{X}$, and $\mathrm{Y}$ are either heteo atoms or carbon

* absolute stereochemistry either $S$ or $R$

Figure 3. General structure of improved aryl hydrophobic head groups as potential EPIs.

\section{Results and Discussion}

Efflux pumps play a prominent role in the multidrug resistance of $P$. aeruginosa and many other Gram-negative bacteria. These efflux pumps have different substrate specificities, and their production and activity can be increased by many factors commonly present in infections. Moreover, many commonly used antibiotics can select mutants that constitutively overproduce efflux pump systems in P. aeruginosa (e.g., fluoroquinolones and aminoglycosides induce the overexpression of MexCD-OprJ and MexXY-OprM, respectively) [26,27]. As such, a standalone antibiotic would face a profound risk of being rendered ineffective almost immediately. Recognizing that efflux pumps contribute significantly to mediating antibiotic resistance in Gram-negative bacteria, TAXIS Pharmaceuticals has focused on the inhibition of these pumps as a first-in-class treatment option where resistance is an issue. Such use of EPIs obviates the need to discover new antibiotics, a strategy that saves a lot of time, effort, and capital associated with discovery and development of antibiotics. Furthermore, this allows clinicians to exploit the already well-established pharmacological properties of known antibiotics. A particularly important implication of EPIs as therapeutic agents is their ability to overcome resistance, thereby enabling the use of already optimized and stockpiled antibiotics. 


\subsection{Screening Results}

The structures of the synthesized heterocyclic carboxamides $\mathbf{6} \mathbf{a}-\mathbf{n}$ that are screened for this study are shown in Table 1.

Table 1. Structures of screened compounds $6 \mathbf{a}-\mathbf{n}$.

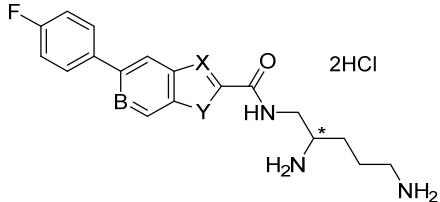

\begin{tabular}{ccccc}
\hline Compound & $\mathbf{X}$ & $\mathbf{Y}$ & $\mathbf{B}$ & $*$ Stereo \\
\hline $\mathbf{6 a}$ & $\mathrm{N}$ & $\mathrm{S}$ & $\mathrm{CH}$ & $S$ \\
$\mathbf{6 c}$ & $\mathrm{N}$ & $\mathrm{NH}$ & $\mathrm{CH}$ & $\mathrm{S}$ \\
$\mathbf{6 d}$ & $\mathrm{N}$ & $\mathrm{NH}$ & $\mathrm{CH}$ & $R$ \\
$\mathbf{6 e}$ & $\mathrm{CH}$ & $\mathrm{O}$ & $\mathrm{CH}$ & $S$ \\
$\mathbf{6 g}$ & $\mathrm{CH}$ & $\mathrm{S}$ & $\mathrm{CH}$ & $S$ \\
$\mathbf{6 i}$ & $\mathrm{CH}$ & $\mathrm{NH}$ & $\mathrm{CH}$ & $\mathrm{S}$ \\
$\mathbf{6 k}$ & $\mathrm{CH}$ & $\mathrm{NH}$ & $\mathrm{CH}$ & $R$ \\
$\mathbf{6 m}$ & $\mathrm{CH}$ & $\mathrm{NH}$ & $\mathrm{N}$ & $S$
\end{tabular}

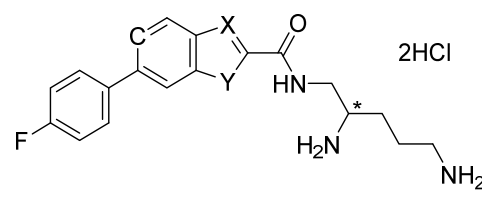

\begin{tabular}{ccccc}
\hline Compound & $\mathbf{X}$ & $\mathbf{Y}$ & $\mathbf{C}$ & * Stereo \\
\hline $\mathbf{6 b}$ & $\mathrm{N}$ & $\mathrm{S}$ & $\mathrm{CH}$ & $\mathrm{S}$ \\
$\mathbf{6 f}$ & $\mathrm{CH}$ & $\mathrm{O}$ & $\mathrm{CH}$ & $\mathrm{S}$ \\
$\mathbf{6 h}$ & $\mathrm{CH}$ & $\mathrm{S}$ & $\mathrm{CH}$ & $\mathrm{S}$ \\
$\mathbf{6 j}$ & $\mathrm{CH}$ & $\mathrm{NH}$ & $\mathrm{CH}$ & $\mathrm{S}$ \\
(TXA01182) & $\mathrm{CH}$ & $\mathrm{NH}$ & $\mathrm{CH}$ & $R$ \\
$\mathbf{6 1}$ & $\mathrm{CH}$ & $\mathrm{NH}$ & $\mathrm{N}$ & $\mathrm{S}$ \\
$\mathbf{6 n}$ & $\mathrm{CH}$ & $\mathrm{H}$ &
\end{tabular}

The carboxamide hydrochloride salts (6a to $6 \mathbf{n}$ ) were first assayed for their antibacterial activities against $P$. aeruginosa ATCC 27853 (Table 2). Except for the two benzothiophene analogs $\mathbf{6 g}$ and $\mathbf{6 h}$ with MICs at $25 \mu \mathrm{g} / \mathrm{mL}$, all the other tested compounds had MICs $\geq 100 \mu \mathrm{g} / \mathrm{mL}$. The ability of heterocyclic carboxamide hydrochloride salts (6a to $\mathbf{6 n}$ ) to lower the MIC of levofloxacin (LVX) was tested. Most compounds potentiated LVX in a concentration-dependent manner (data not shown). The lowest active concentration for the compounds was $6.25 \mu \mathrm{g} / \mathrm{mL}$ (Table 2). Thus, the $6.25 \mu \mathrm{g} / \mathrm{mL}$ concentration was chosen for antimicrobial potentiation assays to ensure that the MICs of the screened compounds did not interfere with their potentiation properties. LVX, as the choice of antimicrobial for the screens, stems from the fact that the P. aeruginosa efflux pumps MexAB-OprM, MexCD-OprJ, MexEF-OprN and MexXY-OprM play an important role in susceptibility to fluoroquinolones in vitro [28-30].

Table 2. Screening results of levofloxacin potentiation by fused heterocyclic carboxamides $(6.25 \mu \mathrm{g} / \mathrm{mL})$ in P. aeruginosa ATCC 27853 *.

\begin{tabular}{|c|c|c|c|c|c|c|c|c|c|c|c|c|c|c|}
\hline Compound & $6 a$ & $6 b$ & $6 c$ & $6 d$ & $6 e$ & $6 f$ & $6 \mathrm{~g}$ & $6 \mathrm{~h}$ & $6 i$ & $6 j$ & 6k & 61 & $6 \mathrm{~m}$ & $6 n$ \\
\hline MIC of EPI $(\mu \mathrm{g} / \mathrm{mL})$ & 100 & $>100$ & 100 & $>100$ & 100 & $>100$ & 25 & 25 & 100 & 100 & $>100$ & 100 & $>100$ & $>100$ \\
\hline $\begin{array}{l}\text { LVX MIC in the presence of EPI } \\
\qquad(\mu \mathrm{g} / \mathrm{mL})\end{array}$ & 1 & 1 & 0.50 & 0.50 & 1 & 0.25 & 0.03 & 0.25 & 0.25 & 0.13 & 0.50 & 0.13 & 1 & 1 \\
\hline Fold Difference & 1 & 1 & 2 & 2 & 1 & 4 & 32 & 4 & 4 & 8 & 2 & 8 & 1 & 1 \\
\hline
\end{tabular}

* MIC of LVX against $P$. aeruginosa ATCC 27853 without EPI $=1 \mu \mathrm{g} / \mathrm{mL}$.

The fused heterocyclic carboxamides were separated into two groups: (1) from zero to weak potentiation (benzothiazole $\mathbf{6 a}$ and $\mathbf{6 b}$, and benzimidazole $\mathbf{6 c}$ and $\mathbf{6 d}$ ) and (2) from moderate to high potentiation (benzothiophene $6 \mathrm{~g}$ and $\mathbf{6 h}$, indole $6 \mathbf{i}$ to $6 \mathbf{l}$ ). Although benzothiophene compound $6 \mathrm{~g}$ showed the highest potency (32-fold at $6.25 \mu \mathrm{g} / \mathrm{mL}$ ), due to its low MIC, this scaffold was discarded from further screening to maintain the strict guideline of at least a 12-fold difference in MIC and the screening concentration. The 6-substituted para-fluorophenyl showed better activity than substitution at 5-position of indoles (6j vs. 6i; 61 vs. 6k). Azaindole analogs 6m and 6 n completely failed to exhibit potentiation as compared to the matched carbon analogs $6 \mathbf{i}$ and $\mathbf{6 j}$. The potentiation of LVX by 3 pairs of enantiomers (6c and $6 \mathbf{d} ; \mathbf{6} \mathbf{i}$ and $6 \mathbf{k} ; \mathbf{6 j}$ and $6 \mathbf{1}$ ) was investigated, while 
the $S$-enantiomer $6 \mathbf{i}$ was 2 -fold better than $R$-enantiomer $6 \mathbf{k}$; the other two pairs of EPI enantiomers did not show any differences in their potentiation effects. The $S$-enantiomer 6j was selected as the model compound for further study due to the easier access to Lornithine than D-ornithine as the starting material for the synthesis of the diamine side chain. It should be pointed out that while the configuration of the chiral amine did not affect the potentiation significantly in this case, the metabolic properties (e.g., metabolic clearance and PK) might vary between the stereoisomers. Screening the active compounds in P. aeruginosa mutants overexpressing MexAB-OprM, MexCD-OprJ, MexEF-OprN and MexXY-OprM did not lead to a significant increase in the potentiation, as seen with the ATCC 27853 strain (Supplemental Table S1). This interesting result might suggest that if the compounds in Table 2 are inhibiting efflux, they might be doing so by acting on a different efflux pump.

\subsection{In-Depth Potentiation Evaluation of $6 j$ (TXA01182)}

Based on the results of the previous screen, one of the most potent compounds $\mathbf{6 j}$, TXA01182, was further studied at $6.25 \mu \mathrm{g} / \mathrm{mL}$ in combination with different classes of antimicrobials in P. aeruginosa ATCC 27853 (Table 3).

Table 3. Potentiation of different classes of antimicrobials by TXA01182 against P. aeruginosa ATCC 27853.

\begin{tabular}{|c|c|c|c|}
\hline \multirow{2}{*}{ Antimicrobial } & \multicolumn{2}{|c|}{ MICs $(\mu \mathrm{g} / \mathrm{mL})$} & \multirow{2}{*}{ Fold Difference } \\
\hline & Alone & + TXA01182 (6.25 $\mu \mathrm{g} / \mathrm{mL})$ & \\
\hline Aztreonam & 8 & 2 & 4 \\
\hline Cefepime & 2 & 1 & 2 \\
\hline Ceftazidime & 2 & 1 & 2 \\
\hline Azithromycin & 64 & 32 & 2 \\
\hline Ciprofloxacin & 0.25 & 0.125 & 2 \\
\hline Moxifloxacin & 2 & 0.063 & 32 \\
\hline Levofloxacin & 1 & 0.125 & 8 \\
\hline Cotrimoxazole & $>256$ & 16 & $>16$ \\
\hline Doxycycline & 32 & 2 & 16 \\
\hline Minocycline & 32 & 1 & 32 \\
\hline Tigecycline & 16 & 4 & 4 \\
\hline Chloramphenicol & $>256$ & 32 & $>8$ \\
\hline Imipenem \# & 4 & 4 & 1 \\
\hline Gentamicin \# & 2 & 2 & 1 \\
\hline
\end{tabular}

\# not the substrates for efflux pumps in P. aeruginosa [31].

Since the initial screening platform utilized levofloxacin, it was not surprising that other fluoroquinolones (ciprofloxacin and moxifloxacin) were also potentiated by TXA01182. The low potentiation (2-fold) with ciprofloxacin could be attributed to its low MIC, or to it being effluxed by a pump not targeted by TXA01182 potentially. TXA01182's effect on tetracycline antimicrobials (doxycycline, minocycline and tigecycline) was pronounced with minocycline, showing 32-fold potentiation. Potentiation of tetracyclines seems to correlate with the efflux liability of these antimicrobials, as minocycline and doxycycline are better substrates to efflux pumps than tigecycline [32-34]. It is noteworthy that TXA01182 potentiates tigecycline 4-fold, bringing its MIC back to a clinically relevant level. As both cotrimoxazole and chloramphenicol fail to show MICs against wild-type $P$. aeruginosa, the ability to see any MIC (16 and $32 \mu \mathrm{g} / \mathrm{mL}$, respectively) in the presence of TXA01182 was encouraging, and in accordance with both antimicrobials being substrates of efflux pumps $[35,36]$. As anticipated for an EPI, imipenem and gentamicin, which are not the substrates of RND efflux pumps in P. aeruginosa, were not potentiated by TXA01182 [37]. The combination with aztreonam, azithromycin, cefepime and ceftazidime with TXA01182 demonstrated only minimal potentiation (2- to 4-fold), suggesting that TXA01182 does not inhibit the pumps responsible for the efflux of these antimicrobials. 


\subsection{TXA01182 Plays a Minimal Role in Membrane Disruption}

To test if the synthetic efforts presented in Table 1 eliminated membrane disruption as a MOA, the possibility of membrane disruption caused by TXA01182 was examined. Membrane disruption was assayed with two approaches: (1) a flow cytometry-based propidium iodide (PI) assay to monitor inner membrane permeabilization, and (2) a nitrocefin (NCF) assay to monitor outer membrane permeabilization. NCF is a chromogenic cephalosporin that changes from yellow to red when the amide bond in the $\beta$-lactam ring is hydrolyzed by a $\beta$-lactamase. The rate of hydrolysis in intact cells is slow as it is limited by the rate of diffusion of periplasmic $\beta$-lactamase across the outer membrane. However, in the presence of an agent that permeabilizes the outer membrane, the rate of hydrolysis will increase [38]. The impact of TXA01182 on NCF hydrolysis is minimal at concentrations below $12.5 \mu \mathrm{g} / \mathrm{mL}$, suggesting that TXA01182 does not interact with the outer membrane of $P$. aeruginosa at these concentrations (Figure 4A). This is a clear improvement from TAXIS' previous scaffolds, which showed clear outer membrane disruption at $3.13 \mu \mathrm{g} / \mathrm{mL}$ [24]. Polymyxin B was used as a positive control (Figure 4B). TXA01182 also did not disrupt the bacterial inner membrane below concentrations of $25 \mu \mathrm{g} / \mathrm{mL}$ compared with DMSO and polymyxin B as vehicle and positive controls, respectively (Figure 4C). In the PI assay, log-phase P. aeruginosa cells were mixed with various concentrations of TXA01182, followed by the addition of PI. Cells whose membranes remain intact exclude PI and remain nonfluorescent, while cells with compromised membrane integrity allow PI to enter and bind to DNA, resulting in fluorescence.
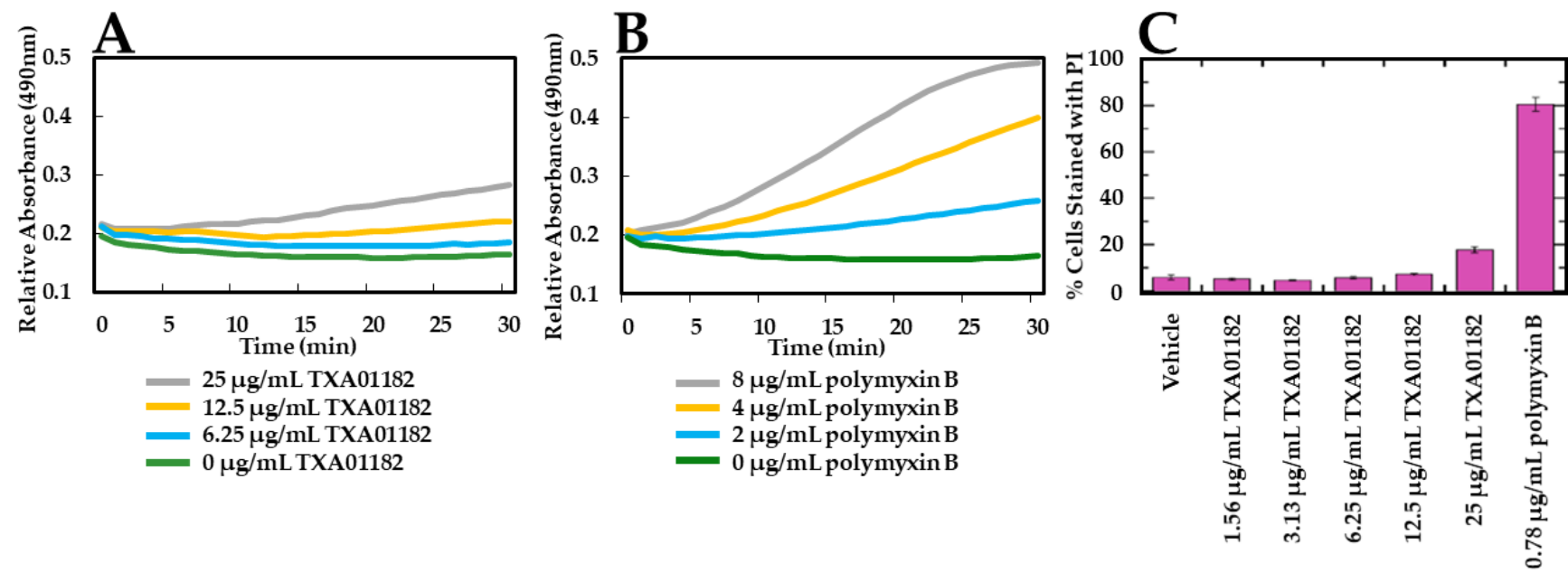

Figure 4. Outer- and inner-membrane permeabilization studies with TXA01182. Basal levels of NCF hydrolysis (A,B) or PI fluorescence $(\mathbf{C})$ are observed upon addition of TXA01182 at concentrations below 12.5 and $25 \mu \mathrm{g} / \mathrm{mL}$, respectively, indicating intact outer and inner membranes.

\subsection{TXA01182 Inhibits the Efflux of Ethidium Bromide}

The efflux of ethidium bromide (EtBr) by P. aeruginosa cells in the presence of TXA01182 was studied in order to establish efflux inhibition as the MOA (Figure 5). Wild- type $P$. aeruginosa PAO1 cells were incubated with EtBr to allow for intracellular accumulation and treated with CCCP to inhibit active efflux. When bound to intracellular bacterial DNA, EtBr fluoresces brightly, while any unbound EtBr outside bacterial cells exhibit little or no fluorescence. Following activation by the addition of glucose, the efflux of EtBr can be followed in real time as a decrease in fluorescence based on the concentration of TXA01182. As seen in Figure 5A, the fluorescence intensity increased proportionally with increasing concentration of TXA01182, indicating intracellular accumulation of EtBr and supporting a role in efflux inhibition by TXA01182. In contrast, polymyxin B, a known membrane disruptor, did not lead to intracellular accumulation of EtBr, in line with its MOA (Figure 5B). 

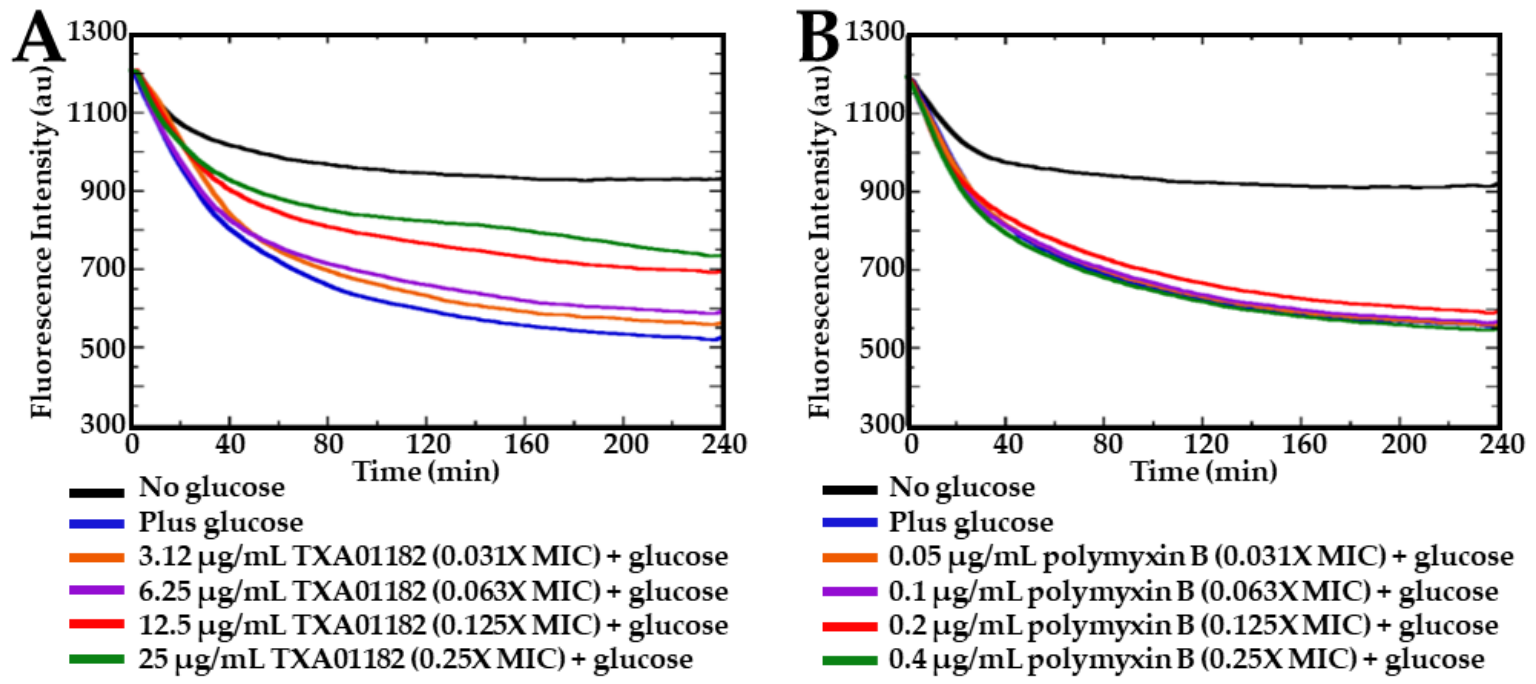

Figure 5. (A) TXA01182 concentration-dependent inhibition of EtBr efflux. (B) polymyxin B does not inhibit EtBr efflux under the same conditions.

\subsection{TXA01182 Enhances the Activity of Levofloxacin against Clinical Isolates of P. aeruginosa}

Eight multidrug-resistant (MDR) P. aeruginosa strains from the CDC and FDA antibiotic resistance isolate bank resistant to levofloxacin (MICs ranging from 8 to $64 \mu \mathrm{g} / \mathrm{mL}$ ) were used to test the EPI activity of TXA01182. The resistance determinants of these strains, including those associated with levofloxacin resistance and efflux upregulation, are shown in Table 4. The gyrA-T83I or gyrA-T133H mutations lead to fluoroquinolone resistance [39-41], while the nalC-G71E and mexR-V126Q mutations are associated with MexAB-OprM overexpression [42-46]. TXA01182 potentiated levofloxacin in all eight resistant isolates from 8- to 32 -fold at $6.25 \mu \mathrm{g} / \mathrm{mL}$. It also potentiated ciprofloxacin and tigecycline from 2- to 16 -fold at the same concentration (Supplemental Table S2). In contrast, MC-04,124, PA $\beta N$ and $\mathrm{CCCP}$, three well characterized EPIs mostly failed to show any potentiation. PA $\beta N$ was able to enhance the activity of levofloxacin 8-fold on two out of six strains (AR-0239 and AR-0249) but at a higher EPI concentration of $50 \mu \mathrm{g} / \mathrm{mL}$. It is noteworthy that the TXA01182 and levofloxacin combination was beneficial against these strains, irrespective of their resistance determinants. The ability of TXA01182 to lower levofloxacin's MIC in these eight resistant clinical isolates suggests that the TXA01182 class of EPI combined with appropriate antimicrobials may be helpful in the fight against multidrug resistant bacteria in the clinic.

Table 4. Levofloxacin potentiation comparison between TXA01182, MC-04,124, PA $\beta N$ and CCCP on multidrug resistant clinical isolates of $P$. aeruginosa.

\begin{tabular}{|c|c|c|c|c|c|c|}
\hline \multirow[b]{2}{*}{ Strain } & \multicolumn{5}{|c|}{ Levofloxacin MIC ( $\mu \mathrm{g} / \mathrm{mL}),($ Fold Difference) } & \multirow[b]{2}{*}{ Resistance Mechanisms } \\
\hline & No EPI & $\begin{array}{l}\text { + TXA01182 } \\
(6.25 \mu \mathrm{g} / \mathrm{mL})\end{array}$ & $\begin{array}{l}+ \text { MC- } 04,124 \\
(6.25 \mu \mathrm{g} / \mathrm{mL})\end{array}$ & $\begin{array}{c}+ \text { PA } \beta N \\
(50 \mu \mathrm{g} / \mathrm{mL})\end{array}$ & $\begin{array}{c}+ \text { CСCР } \\
(12.5 \mu \mathrm{g} / \mathrm{mL})\end{array}$ & \\
\hline AR-0229 & 64 & $4,(16)$ & $64,(1)$ & $64,(1)$ & 64, (1) & $\begin{array}{c}\text { gyrA-T83I, nalC-G71E, } \\
\text { mexR-V126Q, OXA-50, PAO } \\
\text { gyrA-T83I, nalC-G71E, } \\
\text { mexR-V126Q, aac }\left(6^{\prime}\right)-I I a, \text { aadB, } \\
\text { aph(3')-Ic, cmlA1, dfrB5, GES-1, } \\
\text { OXA-10, OXA-50, strA, strB, } \\
\operatorname{tet}(G), \text { VIM-11 }\end{array}$ \\
\hline
\end{tabular}


Table 4. Cont.

\begin{tabular}{|c|c|c|c|c|c|c|}
\hline \multirow[b]{2}{*}{ Strain } & \multicolumn{5}{|c|}{ Levofloxacin MIC ( $\mu \mathrm{g} / \mathrm{mL})$, (Fold Difference) } & \multirow[b]{2}{*}{ Resistance Mechanisms } \\
\hline & No EPI & $\begin{array}{l}+ \text { TXA01182 } \\
(6.25 \mu \mathrm{g} / \mathrm{mL})\end{array}$ & $\begin{array}{l}+\mathrm{MC}-04,124 \\
(6.25 \mu \mathrm{g} / \mathrm{mL})\end{array}$ & $\begin{array}{c}+ \text { PA } \beta N \\
(50 \mu \mathrm{g} / \mathrm{mL})\end{array}$ & $\begin{array}{c}+\mathrm{CCCP} \\
(12.5 \mu \mathrm{g} / \mathrm{mL})\end{array}$ & \\
\hline AR-0244 & 64 & $8,(8)$ & $64,(1)$ & $64,(1)$ & $64,(1)$ & $\begin{array}{c}\text { gyrA-T133H, nalC-G71E, } \\
\text { mexR-V126Q, OXA-50 } \\
\text { gyrA-T83I, nalC-G71E }\end{array}$ \\
\hline AR-0246 & 64 & $8,(8)$ & $64,(1)$ & $64,(1)$ & $64,(1)$ & $\begin{array}{c}\text { mexR-V126Q, aadB, NDM-1, } \\
\text { OXA-10, OXA-50, PAO, rmtD2, } \\
\operatorname{tet}(G), V E B-1\end{array}$ \\
\hline AR-0249 & 64 & $4,(16)$ & $64,(1)$ & $8,(8)$ & $64,(1)$ & $\begin{array}{l}\text { gyrA-T83I, nalC-G71E, aac (3)-Id, } \\
\text { aadA2, cmlA1, dfrB5, OXA-4, } \\
\text { OXA-50,PAO, tet (G), VIM-2 }\end{array}$ \\
\hline AR-0264 & 64 & $4,(16)$ & $64,(1)$ & $64,(1)$ & $64,(1)$ & $\begin{array}{c}\text { gyrA-D87Y, nalC-G71E, OXA-50, } \\
\text { PAO }\end{array}$ \\
\hline AR-0232 & 8 & $0.5,(16)$ & ND & ND & $8,(1)$ & $\begin{array}{c}\text { gyrA-T83I, nalC-G71E, } \\
\text { mexR-V126Q, aadA6, OXA-50, } \\
\text { PAO, strA, strB, sul1, tet }(C)\end{array}$ \\
\hline AR-0234 & 8 & $0.25,(32)$ & ND & ND & $8,(1)$ & $\begin{array}{c}\text { gyrA-T83I, nalC-G71E, } \\
\text { mexR-V126Q, aadA6, OXA-50, } \\
P A O, \operatorname{str} A, \operatorname{str} B, \operatorname{tet}(C)\end{array}$ \\
\hline
\end{tabular}

The nalC-G71E mutation is associated with MexAB-OprM overexpression [42-44]. The mexR-V126Q mutation is associated with MexAB-OprM overexpression [45,46]. The gyrA-T83I or gyrA-T133H mutations lead to fluoroquinolone resistance [39-41]. ND: not determined.

\subsection{TXA01182 Lowers the Frequency of Resistance to Levofloxacin}

In addition to reducing the levels of intrinsic resistance, a potent EPI is also expected to significantly reverse acquired resistance as well as decrease the frequency at which antimicrobial resistance emerges. To test whether TXA01182 in combination with antimicrobials increases the selective pressure on resistant mutant emergence, the effect of TXA01182 on the frequency of resistance (FoR) of P. aeruginosa ATCC 27853 to levofloxacin was tested. TXA01182 reduced the FoR to levofloxacin approximately 500-fold (Table 5). The FoR to TXA01182 alone was close to 1, indicating that it did not affect the growth of P. aeruginosa. TXA01182 also reduced the FoR to cefepime 10-fold (Supplemental Table S3). The undetectable levels of resistance seen in the levofloxacin-TXA01182 combination would be of great value in a clinical setting, particularly in cystic fibrosis patients infected with $P$. aeruginosa, where patients are colonized by hypermutable strains that persist for years [47].

Table 5. Frequency of resistance to TXA01182 and levofloxacin, alone and combination.

\begin{tabular}{cccc}
\hline Strain & $\begin{array}{c}\text { TXA01182 } \\
(6.25 \mu \mathrm{g} / \mathrm{mL})\end{array}$ & $\begin{array}{c}\text { Levofloxacin } \\
(4 \mu \mathrm{g} / \mathrm{mL})\end{array}$ & $\begin{array}{c}\text { Levofloxacin }(4 \mu \mathrm{g} / \mathrm{mL})+ \\
\text { TXA01182 }(6.25 \mu \mathrm{g} / \mathrm{mL})\end{array}$ \\
\hline P. aeruginosa ATCC 27853 & 0.73 & $7.44 \times 10^{-8}$ & $<1.30 \times 10^{-10}$ \\
\hline
\end{tabular}

\subsection{Time-Kill Assay}

In addition to assessing the potentiation activity of TXA01182 in vitro, its potentiation of a minimally bactericidal concentration of levofloxacin (1X MIC) was probed against $P$. aeruginosa ATCC 27853 with time-kill studies. Figure 6 shows time-kill curves with levofloxacin in the absence or presence of TXA01182. By itself, TXA01182 had no effect on the growth of $P$. aeruginosa ATCC 27853 at the highest concentration tested (gray curve). TXA01182 enhanced levofloxacin's killing kinetics in a concentration dependent manner (green and red curves). After $3 \mathrm{~h}$ of incubation, the combination of levofloxacin and TXA01182 killed more bacteria by a magnitude of $>2$-logs compared to levofloxacin alone (orange curve). After $6 \mathrm{~h}$ of incubation, the combination of levofloxacin and TXA01182 
killed more bacteria by a magnitude of $>3$-logs compared to levofloxacin alone. At $24 \mathrm{~h}$, the combination of levofloxacin and TXA01182 achieved almost 6-logs of kill more than levofloxacin alone (orange vs. red curves). These results suggest that the killing kinetics for the combination of levofloxacin and TXA01182 are faster than those of levofloxacin alone. The $24 \mathrm{~h}$ period regrowth associated with antimicrobial resistance was also greatly diminished by the levofloxacin-TXA01182 combination. The potentiation of a minimally bactericidal concentration of levofloxacin (1X MIC) by TXA01182 seen in Figure 6 is consistent with similar studies carried out with a ciprofloxacin-MBX-2319 combination in E. coli [15].

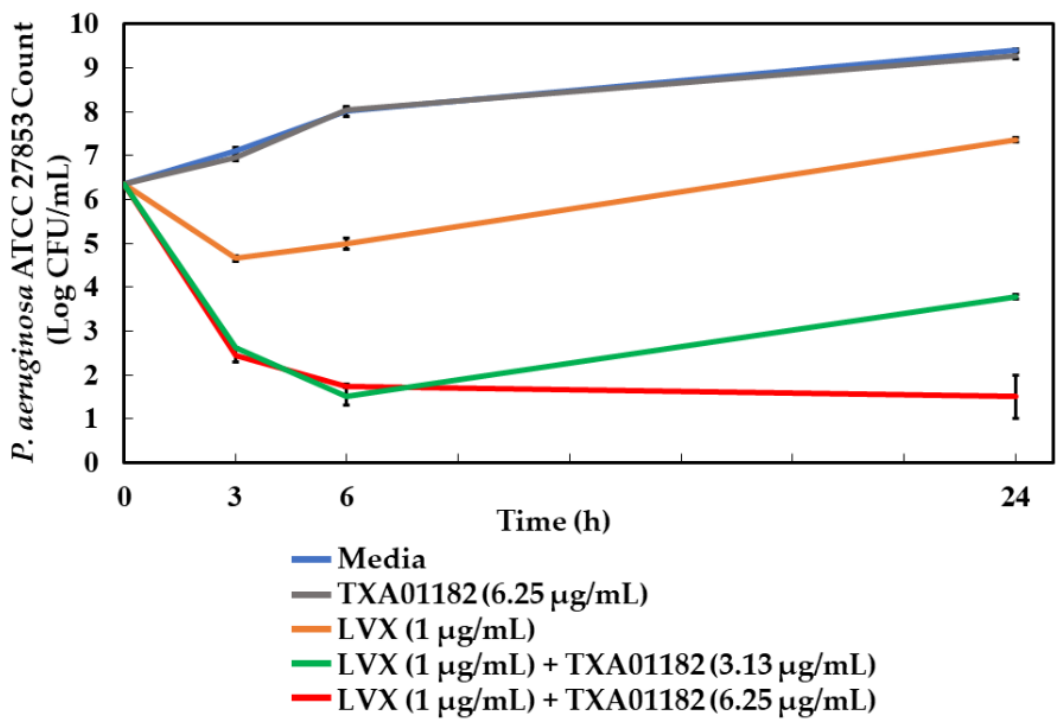

Figure 6. TXA01182 enhances the killing kinetics of levofloxacin (LVX). Time-kill kinetics of LVX alone and in combination with different concentrations of TXA01182 on P. aeruginosa. Values expressed as mean $\log _{10}$ of CFU/mL. Error bars represent standard deviation.

\section{Materials and Methods}

\subsection{Synthesis}

The general synthetic scheme of heterocyclic carboxamides $\mathbf{6 a}-\mathbf{n}$ is outlined in Figure 7. For screening purposes, the chiral center of di-Boc protected pentane diamine was fixed as either $R$ - or $S$ - configuration. SAR found the aryl-linked heterocycles to be superior to the original di-aryl leads (Compounds $\mathbf{1}$ and 2). It is noteworthy to mention that without any aryl substitutions on the fused heterocycles, these compounds were typically devoid of any potentiation activity (data not shown). To improve metabolic stability, para-fluoro substituted aryl boronic acids were typically chosen. Coupling with commercially available or known 5 or 6- bromo-biarylheterocyclic-2-carboxylic methyl or ethyl esters 3 with $p$ fluorophenyl boronic acid under Suzuki reaction conditions afforded the desired esters $\mathbf{4 a - n}$ in high yields. Hydrolysis of the esters to the corresponding heteroaryl acids followed by coupling with the chiral di-Boc amine 5 produced the protected carboxamides. The final compounds were deprotected with $\mathrm{HCl}$ in dioxane to afford the dihydrochloride salts of heterocyclic carboxamides $\mathbf{6 a}-\mathbf{n}$ (Table 1) in excellent yields. The structures of the intermediates and the final compounds were analyzed by ${ }^{1} \mathrm{H}-\mathrm{NMR}$ spectra and LC/MS data. As a representative example, the experimental procedure and spectral data of $\mathbf{6 j}$ (TXA01182) are provided (Figure 8). The spectral data of other compounds can be found in the Supplementary Materials. 


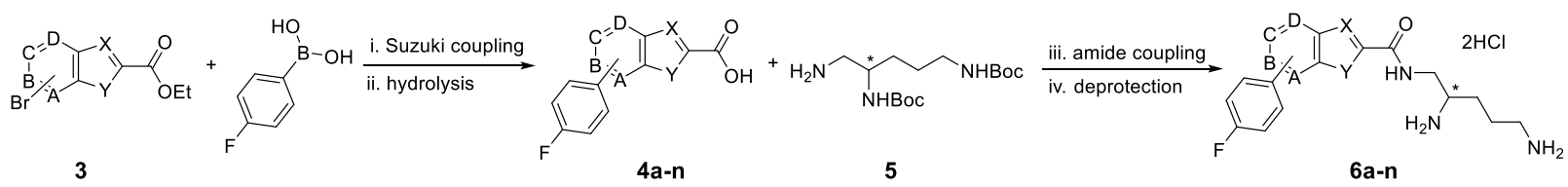

Figure 7. General synthetic scheme for compounds $\mathbf{6 a}-\mathbf{n}$. Reagents and conditions: (i) $\mathrm{Pd}(\mathrm{dppf}) \mathrm{Cl}_{2}$, $\mathrm{Na}_{2} \mathrm{CO}_{3}$, toluene/EtOH $/ \mathrm{H}_{2} \mathrm{O}, 100{ }^{\circ} \mathrm{C}$; (ii) $\mathrm{NaOH}$, THF $/ \mathrm{EtOH} / \mathrm{H}_{2} \mathrm{O}$, r.t. to $60{ }^{\circ} \mathrm{C}$; (iii) $\mathrm{EDCI}, \mathrm{HOBt}$, DIPEA, DMF, r.t.; (iv) $4 \mathrm{M} \mathrm{HCl}$ in dioxane $/ \mathrm{MeOH} .{ }^{*}$ stereo centers.
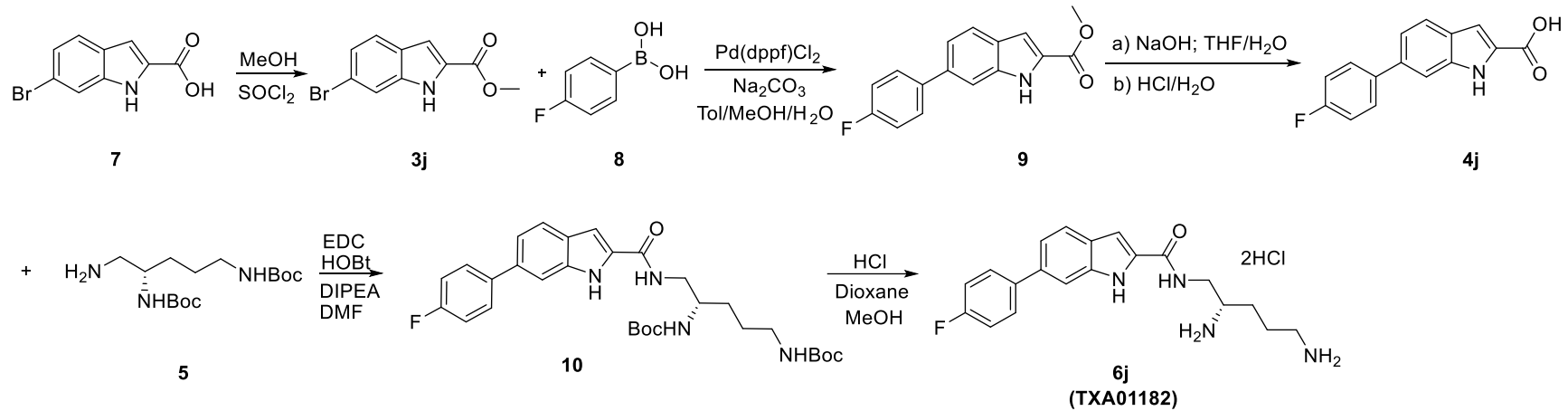

Figure 8. Synthetic scheme for compounds 6j (TXA01182).

Step (1) Synthesis of methyl 6-bromo- $1 H$-indole-2-carboxylate $3 \mathbf{j}$

To a suspension of 6-bromo- $1 \mathrm{H}$-indole-2-carboxylic acid 7 (5.0 g, $20.8 \mathrm{mmol})$ in $\mathrm{MeOH}$ $(100 \mathrm{~mL})$ was added $\mathrm{SOCl}_{2}(2.26 \mathrm{~mL}, 31 \mathrm{mmol})$ very slowly. The mixture was heated under reflux until TLC showed no starting material left. Solvent was removed under vacuo and the crude product was collected as a brown powder (5.2 $\mathrm{g}, 98 \%$ yield) after drying. It was used for next step reaction without purification. ${ }^{1} \mathrm{H}$ NMR $\left(300 \mathrm{MHz}, \mathrm{CDCl}_{3}\right) \delta 8.88$ (s br, $1 \mathrm{H}), 7.59(\mathrm{~s}, 1 \mathrm{H}), 7.55(\mathrm{~d}, J=6 \mathrm{~Hz}, 1 \mathrm{H}), 7.25(\mathrm{~m}, 1 \mathrm{H}), 7.19(\mathrm{~s}, 1 \mathrm{H}), 3.96(\mathrm{~s}, 3 \mathrm{H})$.

Step (2) Synthesis of methyl 6-(4-fluorophenyl)-1H-indole-2-carboxylate 9

The mixture of methyl 6-bromo- $1 H$-indole-2-carboxylate $3 \mathbf{j}$ (510 mg, 2 mmol), (4fluorophenyl)boronic acid $8(520 \mathrm{mg}, 4 \mathrm{mmol})$ in a mixture of toluene, methanol and saturated $\mathrm{Na}_{2} \mathrm{CO}_{3}$ solution $(18 / 4 / 4 \mathrm{~mL})$ was degassed and $\mathrm{Pd}(\mathrm{dppf}) \mathrm{Cl}_{2}(60 \mathrm{mg}, 0.08 \mathrm{mmol})$ was added. The reaction mixture was heated at $100{ }^{\circ} \mathrm{C}$ for $3 \mathrm{hrs}$ and it was extracted with EtOAc and washed with brine and concentrated. Then, it was purified by column chromatography on silica gel (10-30\% ethyl acetate/hexanes) to give the product (390 mg, $72 \%$ yield) as an off-white powder. ${ }^{1} \mathrm{H} \mathrm{NMR}\left(300 \mathrm{MHz}, \mathrm{CDCl}_{3}\right) \delta 8.94(\mathrm{~s} \mathrm{br}, 1 \mathrm{H}), 7.74(\mathrm{~d}$, $J=8.4 \mathrm{~Hz}, 1 \mathrm{H}), 7.62(\mathrm{~m}, 3 \mathrm{H}), 7.36(\mathrm{~d}, J=8.4 \mathrm{~Hz}, 1 \mathrm{H}), 7.24(\mathrm{~m}, 1 \mathrm{H}), 7.15(\mathrm{~m}, 2 \mathrm{H}), 3.96(\mathrm{~s} 3 \mathrm{H})$.

Step (3) Synthesis of 6-(4-fluorophenyl)-1H-indole-2-carboxylic acid $\mathbf{4 j}$

To a solution of methyl 6-(4-fluorophenyl)- $1 H$-indole-2-carboxylate 9 ( $0.35 \mathrm{~g}, 1.3 \mathrm{mmol})$ in $\mathrm{THF}$ was added $\mathrm{NaOH}$ solution $(2 \mathrm{M}, 5 \mathrm{~mL})$. It was stirred at room temperature until no starting material was left. THF was removed under vacuo and the residue was acidified with an $\mathrm{HCl}$ solution. The precipitate was filtered and washed with water. It was dried to provide the product as an off-white powder $(290 \mathrm{mg}, 88 \%$ yield) which was used for next step reaction without further purification. ${ }^{1} \mathrm{H} \mathrm{NMR}\left(300 \mathrm{MHz}, \mathrm{CDCl}_{3}\right) \delta 11.48(\mathrm{~s} \mathrm{br}$, $1 \mathrm{H}), 7.68(\mathrm{~s}, 1 \mathrm{H}), 7.65(\mathrm{~m}, 1 \mathrm{H}), 7.64(\mathrm{~m}, 1 \mathrm{H}), 7.60(\mathrm{~m}, 1 \mathrm{H}), 7.55(\mathrm{~d}, J=8.4 \mathrm{~Hz}, 1 \mathrm{H}), 7.26(\mathrm{~m}$, $1 \mathrm{H}), 7.19(\mathrm{~m}, 1 \mathrm{H}), 6.66(\mathrm{~s}, 1 \mathrm{H})$. MS (ESI-) $\mathrm{m} / \mathrm{z}$ : calcd for $\mathrm{C}_{15} \mathrm{H}_{9} \mathrm{FNO}_{2}$. $[\mathrm{M}-\mathrm{H}]^{-}:$:254.06; found 254.05.

Step (4) Synthesis of di-tert-butyl (5-(6-(4-fluorophenyl)-1H-indole-2-carboxamido) pentane-1,4-diyl)(S)-dicarbamate 10

To a solution of 6-(4-fluorophenyl)- $1 H$-indole-2-carboxylic acid $4 \mathbf{j}$ (60 $\mathrm{mg}, 0.24 \mathrm{mmol})$ in anhydrous DMF $(2 \mathrm{~mL})$ was added DIPEA $(0.09 \mathrm{~mL}, 0.5 \mathrm{mmol}), \mathrm{HOBt}(22 \mathrm{mg}, 0.18 \mathrm{mmol})$ and EDC (45 mg, $0.24 \mathrm{mmol})$. The reaction mixture was stirred at room temperature and ditert-butyl (5-aminopentane-1,4-diyl)(S)-dicarbamate 5 [24] (76 mg, $0.24 \mathrm{mmol})$ was added. 
Stirring of the reaction mixture was continued at room temperature overnight. Then, it was diluted with EtOAc and washed with water and brine. The organic layer was dried over anhydrous sodium sulfate and filtered. The filtrate was concentrated and purified by column chromatography on silica gel (40-60\% ethyl acetate/hexanes) to give the product (75 mg, 57\% yield) as a white solid. ${ }^{1} \mathrm{H}$ NMR (300 MHz, $\left.\mathrm{CDCl}_{3}\right) \delta 7.57(\mathrm{~m}, 1 \mathrm{H}), 7.48(\mathrm{~m}$, $2 \mathrm{H}), 7.33(\mathrm{~m}, 1 \mathrm{H}), 7.18(\mathrm{~d}, J=8.1 \mathrm{~Hz}, 1 \mathrm{H}), 6.99(\mathrm{t}, J=8.1 \mathrm{~Hz}, 2 \mathrm{H}), 6.92(\mathrm{~s}, 1 \mathrm{H}), 5.78(\mathrm{br}, 1 \mathrm{H})$, $3.57(\mathrm{~m}, 1 \mathrm{H}), 3.30(\mathrm{~m}, 2 \mathrm{H}), 2.95(\mathrm{~m}, 2 \mathrm{H}), 1.43(\mathrm{~m}, 4 \mathrm{H}), 1.28(\mathrm{~s}, 9 \mathrm{H}), 1.24(\mathrm{~s}, 9 \mathrm{H})$.

Step (5) Synthesis of (S)-N-(2,5-diaminopentyl)-6-(4-fluorophenyl)-1H-indole-2carboxamide dihydrochloride salt 6j (TXA01182)

To a solution of di-tert-butyl (5-(6-(4-fluorophenyl)-1H-indole-2-carboxamido)pentane1,4-diyl)(S)-dicarbamate 10 (25 mg, $0.045 \mathrm{mmol})$ in $\mathrm{MeOH}(10 \mathrm{~mL}) \mathrm{HCl}$ solution (4 $\mathrm{M}$ in dioxane, $0.2 \mathrm{~mL}$ ) was added. It was stirred at room temperature overnight and solvent was removed under vacuo. The residue was triturated with EtOAc and the precipitate was collected as an off-white powder (15 mg, 70\% yield). ${ }^{1} \mathrm{H}$ NMR (300 MHz, CD $\left.3 \mathrm{OD}\right) \delta 7.69$ $(\mathrm{d}, J=8.4 \mathrm{~Hz}, 1 \mathrm{H}), 7.67(\mathrm{~m}, 1 \mathrm{H}), 7.66(\mathrm{~m}, 2 \mathrm{H}), 7.34(\mathrm{dd}, J=1.8,8.4 \mathrm{~Hz}, 1 \mathrm{H}), 7.21(\mathrm{~s}, 1 \mathrm{H})$, $7.16(\mathrm{t}, J=8.7 \mathrm{~Hz}, 2 \mathrm{H}), 3.76(\mathrm{~m}, 1 \mathrm{H}), 3.62(\mathrm{~m}, 1 \mathrm{H}), 3.50(\mathrm{~m}, 1 \mathrm{H}), 3.02(\mathrm{~m}, 2 \mathrm{H}), 1.87(\mathrm{~m}, 4 \mathrm{H})$. ${ }^{13} \mathrm{C}$ NMR $\left(75 \mathrm{MHz}, \mathrm{CD}_{3} \mathrm{OD}\right) \delta 163.87,160.65,138.10,137.60,136.58,130.76,128.53,128.43$, $126.84,121.94,119.71,115.13,114.84,109.79,104.21,51.85,40.60,38.91,27.15,23.23$. MS (ESI+) $m / z$ : calcd for $\mathrm{C}_{20} \mathrm{H}_{24} \mathrm{FN}_{4} \mathrm{O}[\mathrm{M}+\mathrm{H}]^{+}$: 355.19; found 355.20.

\subsection{Bacterial Strains, Media, and Reagents}

P. aeruginosa ATCC 27853 was obtained from the American Type Culture Collection (ATCC). P. aeruginosa multidrug-resistant isolates AR-0229, AR-0232, AR-0234, AR-0239, AR-0244, AR-0246, AR-0249, AR-0264 were obtained from the CDC and FDA Antibiotic Resistance Isolate Bank. Wild-type P. aeruginosa PAO1 is a common laboratory strain. P. aeruginosa strains K767 (WT), K1455 (mexAB-oprM overexpressed), K2415 (mexXY-oprM overexpressed), K2951 (mexCD-oprJ overexpressed) and K2376 (mexEF-oprN overexpressed) were obtained from Prof. Keith Poole (Queen's University, Kingston, ON, Canada) and have been characterized elsewhere [48-51]. Bacterial cells were grown in cation-adjusted Mueller Hinton (CAMH) media, brain heart infusion broth (BHI) or tryptic soy agar (TSA) plates all obtained from Becton, Dickinson, and Company (BD, Franklin Lakes, NJ, USA). Aztreonam, cefepime, ceftazidime, ciprofloxacin, moxifloxacin, levofloxacin, minocycline, tigecycline, chloramphenicol and imipenem were purchased from TOKU-E (Bellingham, WA, USA). Azithromycin was purchased from Tokyo Chemical Industry (Portland, OR, USA). Cotrimoxazole was purchased from Toronto Research Chemicals (North York, ON, Canada). Doxycycline, gentamicin, phenylalanine-arginine $\beta$-naphthylamide (PA $\beta N$ ) and polymyxin B were purchased from Sigma-Aldrich (St. Louis, MO, USA). Ethidium bromide (EtBr) and glucose were purchased from VWR (Radnor, PA, USA). MC-04,124 was synthesized at TAXIS Pharmaceuticals. Carbonyl cyanide 3-chlorophenylhydrazone (CCCP) was purchased from Enzo Life Sciences (Farmingdale, NY, USA).

\subsection{Minimum Inhibitory Concentration (MIC) Assay for Potentiation of Antimicrobial Activity against $P$. aeruginosa}

An MIC-based assay was used to evaluate the ability of all tested compounds to act as potentiators of antimicrobial activity against $P$. aeruginosa ATCC 27853. MICs were conducted using a protocol similar to that described previously [24]. Log-phase bacteria were added to 96-well microtiter plates (at $5 \times 10^{5}$ colony forming units (CFU) per $\mathrm{mL}$ ) containing two-fold serial dilutions of the antimicrobial in CAMH broth, either in the absence or presence of each test compound $\mathbf{6 a}-\mathbf{n}$ (at a concentration of $6.25 \mu \mathrm{g} / \mathrm{mL}$ ). The final volume in each well was $0.1 \mathrm{~mL}$, and the microtiter plates were incubated aerobically for $18-24 \mathrm{~h}$ at $37^{\circ} \mathrm{C}$. Bacterial growth was then monitored by measuring the optical density (OD) at $600 \mathrm{~nm}$ using a VersaMax ${ }^{\circledR}$ plate reader (Molecular Devices, Inc., Sunnyvale, CA, USA), with the MIC being defined as the lowest antimicrobial concentration at which bacterial growth was inhibited compared to antimicrobial-free and compound-free controls. 
The MIC of each test compound against P. aeruginosa ATCC 27853 was also determined using a similar assay, with the exception that the microtiter plates contained serial dilutions of test compound rather than antimicrobial.

3.4. Fluorescence-Activated Cell Sorting (FACS) Assay for Permeabilization of the Outer and Inner Cell Membranes to Propidium Iodide (PI) in P. aeruginosa

The FACS assay used for assessing the potential of test compounds to permeabilize both the outer and inner cell membranes of P. aeruginosa bacterial cells to PI was conducted as described previously [24]. Log-phase P. aeruginosa ATCC 27853 bacterial cells grown in CAMH broth were diluted in PBS to a concentration of $4 \times 10^{6} \mathrm{CFU} / \mathrm{mL}$. The bacteria were aliquoted into tubes and mixed with TXA01182 at concentrations ranging from 1/4th to $1 / 64$ th times the MIC (25 to $1.56 \mu \mathrm{g} / \mathrm{mL}$ ). DMSO alone was used as a solvent control. Polymyxin B was used as a positive control. All test concentrations and controls were prepared in triplicate. PI was then added to all tubes at a final concentration of $50 \mu \mathrm{M}$, and the samples were incubated in the dark at room temperature for $1 \mathrm{~h}$. Intracellular PI fluorescence was detected by flow cytometry using a Gallios Cytometer (Beckman Coulter Inc., Indianapolis, IN, USA). The $488 \mathrm{~nm}$ laser was used for excitation, with the $620 / 630 \mathrm{~nm}$ channel being used for emission. For each sample, the fluorescence of 30,000 individual bacterial cells was measured, and the percent of cells that stained positive for PI fluorescence was calculated.

\subsection{Nitrocefin (NCF) Cellular Assay for Outer Cell Membrane Permeabilization Assessment in $P$. aeruginosa}

P. aeruginosa ATCC 27853 was incubated with imipenem 1/4th MIC overnight to induce the expression of chromosomal $\beta$-lactamase in CAMH media. Cells were harvested, washed in $10 \mathrm{mM}$ HEPES, $2.5 \mathrm{mM} \mathrm{MgCl}_{2}, \mathrm{pH}=7$ buffer and resuspended in the same buffer at an $\mathrm{OD}_{600}$ of approximately 0.5 . Then, $100 \mu \mathrm{L}$ of the cell suspension were mixed with $50 \mu \mathrm{L}$ of either TXA01182 or polymyxin B to give a final concentration of 0 to $25 \mu \mathrm{g} / \mathrm{mL}$, or 0 to $8 \mu \mathrm{g} / \mathrm{mL}$, respectively. Next, $50 \mu \mathrm{L}$ of nitrocefin was added to reach a final concentration of $32 \mu \mathrm{g} / \mathrm{mL}$. Hydrolysis of nitrocefin was monitored spectrophotometrically by measurement of the increase in absorbance at $490 \mathrm{~nm}$. Assays were performed in 96-well plates in a SpectraMax iD5 spectrophotometer (Molecular Devices, Sunnyvale, CA, USA).

\subsection{Fluorescence-Based Cellular Assay for Inhibition of Pump-Mediated Efflux of Ethidium Bromide $(\mathrm{EtBr})$}

The potential of TXA01182 to inhibit efflux pumps in P. aeruginosa was evaluated using a fluorescence-based cellular assay that measures the pump-mediated efflux of EtBr [24,52]. In this assay, P. aeruginosa PAO1 cells were harvested from overnight cultures by centrifugation, and the cell pellets were washed with PBS containing $1 \mathrm{mM} \mathrm{MgCl} 2$ (PBSM). After washing the cells, the cell pellets were resuspended in PBSM to achieve a final $\mathrm{OD}_{600}$ of 1.0. The proton gradient required for RND efflux pumps to function was then uncoupled by addition of carbonyl cyanide 3-chlorophenylhydrazone (CCCP) to a final concentration of $50 \mu \mathrm{M}$, along with the addition of EtBr at a final concentration of $200 \mu \mathrm{M}$. Cells were then incubated in the dark at $37^{\circ} \mathrm{C}$ for $50 \mathrm{~min}$ to allow for EtBr to accumulate inside cells. Then, $200 \mu \mathrm{L}$ aliquots of the bacterial suspension were distributed into wells of a black, flat-bottom 96-well plate containing TXA01182 at concentrations ranging from $1 / 4$ th to $1 / 32$ nd times the MIC (25 to $3.13 \mu \mathrm{g} / \mathrm{mL}$ ), or an equivalent volume of the vehicle (DMSO) alone. A plate vortexer was used to mix the bacterial cells with the test compounds. After pre-incubation at $37^{\circ} \mathrm{C}$ for $5 \mathrm{~min}$, efflux pump activity was initiated by reenergizing the bacterial cells with the addition of glucose to a final concentration of $100 \mathrm{mM}$. EtBr efflux was monitored using a SpectraMax ${ }^{\circledR} 2$ fluorescent plate reader (Molecular Devices, Inc., Sunnyvale, CA, USA) to measure the fluorescence of each well at $37{ }^{\circ} \mathrm{C}$ once per minute for $240 \mathrm{~min}$. The excitation and emission wavelengths were set at 510 and $620 \mathrm{~nm}$, respectively. 


\subsection{Frequency of Resistance (FoR) Studies}

The FoR of $P$. aeruginosa to levofloxacin or cefepime alone, or in combination with TXA01182, was assayed by using a large-inoculum approach described previously [53]. Tryptic soy agar plates were prepared containing $4 \mu \mathrm{g} / \mathrm{mL}$ levofloxacin alone (four times the MIC), $4 \mu \mathrm{g} / \mathrm{mL}$ levofloxacin plus $6.25 \mu \mathrm{g} / \mathrm{mL}$ TXA01182, $2 \mu \mathrm{g} / \mathrm{mL}$ cefepime alone (two times the MIC), $2 \mu \mathrm{g} / \mathrm{mL}$ cefepime plus $6.25 \mu \mathrm{g} / \mathrm{mL}$ TXA01182, or DMSO alone. All plates were incubated at $37^{\circ} \mathrm{C}$ and examined after $72 \mathrm{~h}$. FoR was calculated by dividing the number of resistant colonies growing on antimicrobial-containing plates, or antimicrobial plus TXA01182-containing plates by the total number of CFU in the initial test inoculum.

\subsection{Time-Kill Studies}

Time-kill studies were performed according to previously published methods [54]. Briefly, freshly prepared colonies were resuspended in $5 \mathrm{~mL}$ of BHI and incubated with shaking $\left(37^{\circ} \mathrm{C}, 180 \mathrm{rpm}\right)$ overnight. Cultures were then diluted to $5 \times 10^{6} \mathrm{CFU} / \mathrm{mL}$. When indicated, levofloxacin was added to the prepared bacterial suspensions at one time the MIC $(1 \mu \mathrm{g} / \mathrm{mL})$. TXA01182 was added to bacterial suspensions at 1/16th, 1/25th and $1 / 32$ nd times the MIC $(6.25 \mu \mathrm{g} / \mathrm{mL}, 4 \mu \mathrm{g} / \mathrm{mL}$, and $3.125 \mu \mathrm{g} / \mathrm{mL}$, respectively). A growth control with only media was included. Controls with only levofloxacin or TXA01182 were also included. The starting inoculum was determined from the growth control tube immediately after dilution and was recorded as the count at time zero. Cultures were incubated with shaking $\left(37^{\circ} \mathrm{C}, 180 \mathrm{rpm}\right)$, and viability counts were performed at 3,6 , and $24 \mathrm{~h}$ by plating serial dilutions on tryptic soy agar (TSA). TSA plates were incubated at $37^{\circ} \mathrm{C}$ for at least $18 \mathrm{~h}$. Colonies were counted, and the results were recorded as the number of $\mathrm{CFU} / \mathrm{mL}$.

\section{Conclusions}

As global resistance to conventional antibiotics rises, in part, by efflux-mediated mechanisms, new strategies are needed to develop future novel therapeutics. A promising strategy for combating efflux-mediated resistance is the combination of antimicrobials with indirect antimicrobial agents such as EPIs. Thus, there is an urgent need for effective efflux inhibitors that can restore the activity of conventional antibiotics. The aim of this program was to discover novel EPIs active against $P$. aeruginos $a$ within a heterocyclic-carboxamide series. A variety of fused heterocyclic carboxamides were synthesized and screened for their potentiation effect on levofloxacin against P. aeruginosa ATCC 27853. The 2-carboxamide indole compound $\mathbf{6 j}$ (TXA01182) potentiated levofloxacin prominently, while other heterocyclic carboxamides were either inactive or had a low potentiation effect. Based on the good potentiation ability of TXA01182 on levofloxacin, it was further evaluated in combination with different classes of antimicrobials. The MOA of this hit compound was studied biophysically to prove that it acts as an EPI in P. aeruginosa. Inhibition by TXA01182 of an efflux pump yet to be identified appears to be of clinical relevance, since the susceptibility of MDR P. aeruginosa clinical isolates to levofloxacin and tigecycline is increased significantly by TXA01182. Identification of the efflux pump(s) targeted by TXA01182, and its analogs, is still ongoing. In terms of druggable properties, indole-containing EPIs similar to TXA01182, which are currently under development, are particularly promising on the basis of their lower lipophilicity, excellent solubility, and high metabolic stability (data not shown). Attenuating the $\mathrm{pKa}$ of both the amines while retaining the potentiation effects of these EPIs might reduce the risks of any amine induced toxicity, including cardiotoxicity and nephrotoxicity, during developmental phases. The detailed SAR studies and optimization efforts within this class of EPIs will be reported after this publication. The results of the studies, with selected optimized candidates involving broad-spectrum potentiation abilities, detailed MOA, improvement of toxicity profile, including hERG binding by structure property relationship, PK parameters and, lastly, in vivo efficacy, and will be published in due course. 


\section{Patents}

Some works of this study are published in the following patent applications: LaVoie, E.; Parhi, A.; Yuan, Y.; Zhang, Y.; Sun, Y. Indole Derivatives as Efflux Pump Inhibitors. WO2018165611. LaVoie, E.; Parhi, A.; Zhang, Y.; Yuan, Y.; Sun, Y. Bacterial Efflux Pump Inhibitors. WO2018165612.

Supplementary Materials: The following are available online at https://www.mdpi.com/article/ 10.3390/antibiotics11010030/s1, Table S1: Levofloxacin potentiation in the presence of EPI on $P$. aeruginosa strains overexpressing efflux pumps; Table S2: Ciprofloxacin and tigecycline potentiation in the presence of TXA01182 on multidrug resistant clinical isolates; Table S3: Frequency of resistance to Cefepime alone and in combination with TXA01182.

Author Contributions: A.K.P., Y.Y. and J.D.R.-L. designed the study, drafted and wrote the manuscript; Y.Y., Y.Z. and Y.S. performed the synthesis and the NMR and LC-MS analysis; J.D.R.-L., P.D., Y.C. and A.B. performed antimicrobial analysis. A.K.P. supervised this study. All authors have read and agreed to the published version of the manuscript.

Funding: This research is supported by the Cooperative Agreement Number IDSEP160030 from ASPR/BARDA and by awards from Wellcome Trust, and Germany's Federal Ministry of Education and Research. The contents are solely the responsibility of the authors and do not necessarily represent the official views of the HHS Office of the Assistant Secretary for Preparedness and Response, or other CARB-X funders.

Data Availability Statement: Data is contained within the article or Supplementary Material.

Acknowledgments: We are grateful to Edmond J. LaVoie, Daniel Pilch and Malvika Kaul for their valuable contributions to this study. We thank Marshall Morningstar for his help in preparing this manuscript.

Conflicts of Interest: All the authors are associated with TAXIS Pharmaceuticals Inc. and thus declare conflict of interest.

\section{References}

1. Amaral, L.; Martins, A.; Spengler, G.; Molnar, J. Efflux pumps of Gram-negative bacteria: What they do, how they do it, with what and how to deal with them. Front. Pharmacol. 2014, 4, 168. [CrossRef]

2. Li, X.Z.; Nikaido, H. Efflux-mediated drug resistance in bacteria. Drugs 2004, 64, 159-204. [CrossRef]

3. Nikaido, H.; Pages, J.M. Broad-specificity efflux pumps and their role in multidrug resistance of Gram-negative bacteria. FEMS Microbiol. Rev. 2012, 36, 340-363. [CrossRef]

4. Colclough, A.L.; Alav, I.; Whittle, E.E.; Pugh, H.L.; Darby, E.M.; Legood, S.W.; McNeil, H.E.; Blair, J.M. RND efflux pumps in Gram-negative bacteria; regulation, structure and role in antibiotic resistance. Future Microbiol. 2020, 15, 143-157. [CrossRef]

5. Daury, L.; Orange, F.; Taveau, J.C.; Verchere, A.; Monlezun, L.; Gounou, C.; Marreddy, R.K.; Picard, M.; Broutin, I.; Pos, K.M.; et al. Tripartite assembly of RND multidrug efflux pumps. Nat. Commun. 2016, 7, 10731. [CrossRef] [PubMed]

6. Poole, K. Multidrug efflux pumps and antimicrobial resistance in Pseudomonas aeruginosa and related organisms. J. Mol. Microbiol. Biotechnol. 2001, 3, 255-264.

7. Poole, K.; Srikumar, R. Multidrug efflux in Pseudomonas aeruginosa: Components, mechanisms and clinical significance. Curr. Top. Med. Chem. 2001, 1, 59-71. [CrossRef]

8. Serra, C.; Bouharkat, B.; Tir Touil-Meddah, A.; Guenin, S.; Mullie, C. MexXY Multidrug Efflux System Is More Frequently Overexpressed in Ciprofloxacin Resistant French Clinical Isolates Compared to Hospital Environment Ones. Front. Microbiol. 2019, 10, 366. [CrossRef]

9. Lister, P.D.; Wolter, D.J.; Hanson, N.D. Antibacterial-resistant Pseudomonas aeruginosa: Clinical impact and complex regulation of chromosomally encoded resistance mechanisms. Clin. Microbiol. Rev. 2009, 22, 582-610. [CrossRef]

10. Blanco, P.; Sanz-Garcia, F.; Hernando-Amado, S.; Martinez, J.L.; Alcalde-Rico, M. The development of efflux pump inhibitors to treat Gram-negative infections. Expert Opin. Drug Discov. 2018, 13, 919-931. [CrossRef]

11. Wang, Y.; Venter, H.; Ma, S. Efflux Pump Inhibitors: A Novel Approach to Combat Efflux-Mediated Drug Resistance in Bacteria. Curr. Drug Targets 2016, 17, 702-719. [CrossRef]

12. Pages, J.M.; Masi, M.; Barbe, J. Inhibitors of efflux pumps in Gram-negative bacteria. Trends Mol. Med. 2005, 11, 382-389. [CrossRef] [PubMed]

13. Lomovskaya, O.; Warren, M.S.; Lee, A.; Galazzo, J.; Fronko, R.; Lee, M.; Blais, J.; Cho, D.; Chamberland, S.; Renau, T.; et al Identification and characterization of inhibitors of multidrug resistance efflux pumps in Pseudomonas aeruginosa: Novel agents for combination therapy. Antimicrob. Agents Chemother. 2001, 45, 105-116. [CrossRef] 
14. Renau, T.E.; Leger, R.; Filonova, L.; Flamme, E.M.; Wang, M.; Yen, R.; Madsen, D.; Griffith, D.; Chamberland, S.; Dudley, M.N.; et al. Conformationally-restricted analogues of efflux pump inhibitors that potentiate the activity of levofloxacin in Pseudomonas aeruginosa. Bioorg. Med. Chem. Lett. 2003, 13, 2755-2758. [CrossRef]

15. Yoshida, K.; Nakayama, K.; Ohtsuka, M.; Kuru, N.; Yokomizo, Y.; Sakamoto, A.; Takemura, M.; Hoshino, K.; Kanda, H.; Nitanai, H.; et al. MexAB-OprM specific efflux pump inhibitors in Pseudomonas aeruginosa. Part 7: Highly soluble and in vivo active quaternary ammonium analogue D13-9001, a potential preclinical candidate. Bioorg. Med. Chem. 2007, 15, 7087-7097. [CrossRef]

16. Opperman, T.J.; Kwasny, S.M.; Kim, H.S.; Nguyen, S.T.; Houseweart, C.; D'Souza, S.; Walker, G.C.; Peet, N.P.; Nikaido, H.; Bowlin, T.L. Characterization of a novel pyranopyridine inhibitor of the AcrAB efflux pump of Escherichia coli. Antimicrob. Agents Chemother. 2014, 58, 722-733. [CrossRef]

17. Lomovskaya, O.; Bostian, K.A. Practical applications and feasibility of efflux pump inhibitors in the clinic-A vision for applied use. Biochem. Pharmacol. 2006, 71, 910-918. [CrossRef]

18. Farrell, L.J.; Lo, R.; Wanford, J.J.; Jenkins, A.; Maxwell, A.; Piddock, L.J.V. Revitalizing the drug pipeline: AntibioticDB, an open access database to aid antibacterial research and development. J. Antimicrob. Chemother. 2018, 73, 2284-2297. [CrossRef]

19. Li, X.Z.; Plesiat, P.; Nikaido, H. The challenge of efflux-mediated antibiotic resistance in Gram-negative bacteria. Clin. Microbiol. Rev. 2015, 28, 337-418. [CrossRef]

20. Mahmood, H.Y.; Jamshidi, S.; Sutton, J.M.; Rahman, K.M. Current Advances in Developing Inhibitors of Bacterial Multidrug Efflux Pumps. Curr. Med. Chem. 2016, 23, 1062-1081. [CrossRef]

21. Schweizer, H.P. Understanding efflux in Gram-negative bacteria: Opportunities for drug discovery. Expert Opin. Drug Discov. 2012, 7, 633-642. [CrossRef] [PubMed]

22. De Oliveira, D.M.P.; Forde, B.M.; Kidd, T.J.; Harris, P.N.A.; Schembri, M.A.; Beatson, S.A.; Paterson, D.L.; Walker, M.J. Antimicrobial Resistance in ESKAPE Pathogens. Clin. Microbiol. Rev. 2020, 33, e00181-19. [CrossRef]

23. TAXIS Pharmaceuticals, Inc. Tackling resistance in multidrug-resistant bacterial infections. Biopharma Deal. 2020, 14. Available online: www.nature.com/articles/d43747-020-00935-2 (accessed on 1 November 2021).

24. Blankson, G.; Parhi, A.K.; Kaul, M.; Pilch, D.S.; LaVoie, E.J. Structure-activity relationships of potentiators of the antibiotic activity of clarithromycin against Escherichia coli. Eur. J. Med. Chem. 2019, 178, 30-38. [CrossRef]

25. Blankson, G.A.; Parhi, A.K.; Kaul, M.; Pilch, D.S.; LaVoie, E.J. Advances in the structural studies of antibiotic potentiators against Escherichia coli. Bioorg. Med. Chem. 2019, 27, 3254-3278. [CrossRef] [PubMed]

26. Zhao, L.; Wang, S.; Li, X.; He, X.; Jian, L. Development of in vitro resistance to fluoroquinolones in Pseudomonas aeruginosa. Antimicrob. Resist. Infect. Control 2020, 9, 124. [CrossRef]

27. Poole, K. Efflux-mediated antimicrobial resistance. J. Antimicrob. Chemother. 2005, 56, 20-51. [CrossRef]

28. Kohler, T.; Michea-Hamzehpour, M.; Henze, U.; Gotoh, N.; Curty, L.K.; Pechere, J.C. Characterization of MexE-MexF-OprN, a positively regulated multidrug efflux system of Pseudomonas aeruginosa. Mol. Microbiol. 1997, 23, 345-354. [CrossRef]

29. Masuda, N.; Sakagawa, E.; Ohya, S.; Gotoh, N.; Tsujimoto, H.; Nishino, T. Substrate specificities of MexAB-OprM, MexCD-OprJ, and MexXY-oprM efflux pumps in Pseudomonas aeruginosa. Antimicrob. Agents Chemother. 2000, 44, 3322-3327. [CrossRef]

30. Zhang, L.; Li, X.Z.; Poole, K. Fluoroquinolone susceptibilities of efflux-mediated multidrug-resistant Pseudomonas aeruginosa, Stenotrophomonas maltophilia and Burkholderia cepacia. J. Antimicrob. Chemother. 2001, 48, 549-552. [CrossRef] [PubMed]

31. Avrain, L.; Mertens, P.; Van Bambeke, F. RND efflux pumps in P. aeruginosa: An underestimated resistance mechanism. Antibiot. Susceptibility 2013, 26321, 26-28.

32. Dean, C.R.; Visalli, M.A.; Projan, S.J.; Sum, P.E.; Bradford, P.A. Efflux-mediated resistance to tigecycline (GAR-936) in Pseudomonas aeruginosa PAO1. Antimicrob. Agents Chemother. 2003, 47, 972-978. [CrossRef] [PubMed]

33. Fluit, A.C.; Florijn, A.; Verhoef, J.; Milatovic, D. Presence of tetracycline resistance determinants and susceptibility to tigecycline and minocycline. Antimicrob. Agents Chemother. 2005, 49, 1636-1638. [CrossRef] [PubMed]

34. Petersen, P.J.; Jacobus, N.V.; Weiss, W.J.; Sum, P.E.; Testa, R.T. In vitro and in vivo antibacterial activities of a novel glycylcycline, the 9-t-butylglycylamido derivative of minocycline (GAR-936). Antimicrob. Agents Chemother. 1999, 43, 738-744. [CrossRef] [PubMed]

35. Kohler, T.; Kok, M.; Michea-Hamzehpour, M.; Plesiat, P.; Gotoh, N.; Nishino, T.; Curty, L.K.; Pechere, J.C. Multidrug efflux in intrinsic resistance to trimethoprim and sulfamethoxazole in Pseudomonas aeruginosa. Antimicrob. Agents Chemother. 1996, 40, 2288-2290. [CrossRef] [PubMed]

36. Li, X.Z.; Livermore, D.M.; Nikaido, H. Role of efflux pump(s) in intrinsic resistance of Pseudomonas aeruginosa: Resistance to tetracycline, chloramphenicol, and norfloxacin. Antimicrob. Agents Chemother. 1994, 38, 1732-1741. [CrossRef]

37. Kohler, T.; Michea-Hamzehpour, M.; Epp, S.F.; Pechere, J.C. Carbapenem activities against Pseudomonas aeruginosa: Respective contributions of OprD and efflux systems. Antimicrob. Agents Chemother. 1999, 43, 424-427. [CrossRef] [PubMed]

38. Hancock, R.E.; Wong, P.G. Compounds which increase the permeability of the Pseudomonas aeruginosa outer membrane. Antimicrob. Agents Chemother. 1984, 26, 48-52. [CrossRef]

39. Bruchmann, S.; Dotsch, A.; Nouri, B.; Chaberny, I.F.; Haussler, S. Quantitative contributions of target alteration and decreased drug accumulation to Pseudomonas aeruginosa fluoroquinolone resistance. Antimicrob. Agents Chemother. 2013, 57, 1361-1368. [CrossRef] 
40. Nguyen, K.V.; Nguyen, T.V.; Nguyen, H.T.T.; Le, D.V. Mutations in the gyrA, parC, and mexR genes provide functional insights into the fluoroquinolone-resistant Pseudomonas aeruginosa isolated in Vietnam. Infect. Drug Resist. 2018, 11, 275-282. [CrossRef] [PubMed]

41. Kugelberg, E.; Lofmark, S.; Wretlind, B.; Andersson, D.I. Reduction of the fitness burden of quinolone resistance in Pseudomonas aeruginosa. J. Antimicrob. Chemother. 2005, 55, 22-30. [CrossRef]

42. Braz, V.S.; Furlan, J.P.; Fernandes, A.F.; Stehling, E.G. Mutations in NalC induce MexAB-OprM overexpression resulting in high level of aztreonam resistance in environmental isolates of Pseudomonas aeruginosa. FEMS Microbiol. Lett. 2016, 363. [CrossRef]

43. Maeda, T.; Garcia-Contreras, R.; Pu, M.; Sheng, L.; Garcia, L.R.; Tomas, M.; Wood, T.K. Quorum quenching quandary: Resistance to antivirulence compounds. ISME J. 2012, 6, 493-501. [CrossRef]

44. Pan, Y.P.; Xu, Y.H.; Wang, Z.X.; Fang, Y.P.; Shen, J.L. Overexpression of MexAB-OprM efflux pump in carbapenem-resistant Pseudomonas aeruginosa. Arch. Microbiol. 2016, 198, 565-571. [CrossRef]

45. Choudhury, D.; Ghose, A.; Dhar Chanda, D.; Das Talukdar, A.; Dutta Choudhury, M.; Paul, D.; Maurya, A.P.; Chakravarty, A.; Bhattacharjee, A. Premature Termination of MexR Leads to Overexpression of MexAB-OprM Efflux Pump in Pseudomonas aeruginosa in a Tertiary Referral Hospital in India. PLoS ONE 2016, 11, e0149156. [CrossRef]

46. Pai, H.; Kim, J.; Kim, J.; Lee, J.H.; Choe, K.W.; Gotoh, N. Carbapenem resistance mechanisms in Pseudomonas aeruginosa clinical isolates. Antimicrob. Agents Chemother. 2001, 45, 480-484. [CrossRef] [PubMed]

47. Oliver, A.; Canton, R.; Campo, P.; Baquero, F.; Blazquez, J. High frequency of hypermutable Pseudomonas aeruginosa in cystic fibrosis lung infection. Science 2000, 288, 1251-1254. [CrossRef] [PubMed]

48. Srikumar, R.; Paul, C.J.; Poole, K. Influence of mutations in the mexR repressor gene on expression of the MexA-MexB-oprM multidrug efflux system of Pseudomonas aeruginosa. J. Bacteriol. 2000, 182, 1410-1414. [CrossRef]

49. Morita, Y.; Sobel, M.L.; Poole, K. Antibiotic inducibility of the MexXY multidrug efflux system of Pseudomonas aeruginosa: Involvement of the antibiotic-inducible PA5471 gene product. J. Bacteriol. 2006, 188, 1847-1855. [CrossRef] [PubMed]

50. Purssell, A.; Poole, K. Functional characterization of the NfxB repressor of the mexCD-oprJ multidrug efflux operon of Pseudomonas aeruginosa. Microbiology 2013, 159, 2058-2073. [CrossRef]

51. Fetar, H.; Gilmour, C.; Klinoski, R.; Daigle, D.M.; Dean, C.R.; Poole, K. mexEF-oprN multidrug efflux operon of Pseudomonas aeruginosa: Regulation by the MexT activator in response to nitrosative stress and chloramphenicol. Antimicrob. Agents Chemother. 2011, 55, 508-514. [CrossRef] [PubMed]

52. Paixao, L.; Rodrigues, L.; Couto, I.; Martins, M.; Fernandes, P.; de Carvalho, C.C.; Monteiro, G.A.; Sansonetty, F.; Amaral, L.; Viveiros, M. Fluorometric determination of ethidium bromide efflux kinetics in Escherichia coli. J. Biol. Eng. 2009, 3, 18. [CrossRef] [PubMed]

53. Kaul, M.; Mark, L.; Zhang, Y.; Parhi, A.K.; LaVoie, E.J.; Pilch, D.S. Pharmacokinetics and in vivo antistaphylococcal efficacy of TXY541, a 1-methylpiperidine-4-carboxamide prodrug of PC190723. Biochem. Pharmacol. 2013, 86, 1699-1707. [CrossRef]

54. Keepers, T.R.; Gomez, M.; Celeri, C.; Nichols, W.W.; Krause, K.M. Bactericidal activity, absence of serum effect, and time-kill kinetics of ceftazidime-avibactam against beta-lactamase-producing Enterobacteriaceae and Pseudomonas aeruginosa. Antimicrob. Agents Chemother. 2014, 58, 5297-5305. [CrossRef] [PubMed] 